\title{
Poor oral habits and malocclusions after usage of orthodontic pacifiers: an observational study on 3-5 years old children
}

Silvia Caruso ${ }^{1}$, Alessandro Nota ${ }^{1,2}$, Atanaz Darvizeh ${ }^{2}$, Marco Severino ${ }^{1}$, Roberto Gatto ${ }^{1}$ and Simona Tecco ${ }^{2^{*}}$ (1)

\begin{abstract}
Background: Pacifier sucking habit has been associated in the literature with alterations of dental occlusion, and it could be a predisposing factor for other poor oral habits among children. Orthodontic pacifiers have been introduced in the market aiming to reduce these disadvantages caused by the conventional type of pacifiers. The aim of this study was to evaluate the prevalence of poor oral habits and malocclusions, after usage of orthodontic pacifiers in children with primary dentition.

Methods: A sample of 198 pre-school children, aged 3-5 years, (96 males and 102 females) who had exclusively used an orthodontic pacifier were included in order to assess the level of poor oral habits and the absence/ presence of dental malocclusion. Firstly, children's parents/legal guardians were given a validated questionnaire, then the children were clinically examined at a dental clinic.

Results: Most of the children (79.79\%) had started using the orthodontic pacifier within the first 3 months of life, and the $43.49 \%$ of them continued using it over a period of 2 years. The recorded percentage for those who had used it throughout sleep was $89.39 \%$. Mouth breathing during the night was reported for $36.04 \%$ of the children. Tongue thrust swallow affected $16.16 \%$ of the sample. The $5.56 \%$ of the data indicated the presence of fingersucking/thumbsucking habit. The noted percentages for children with lip biting, lingual interposition between teeth at rest and those with nail biting, were 5.56, 12.63 and 15.15\%, respectively. The regression revealed a significant contribution between early start of using an orthodontic pacifier with the prevalence of fingersucking/thumbsucking (OR $0.13,95 \% \mathrm{Cl} 0.04-0.47, p=0.0004)$. This also reported a noticeable increase of the malocclusion prevalence among the female gender (OR 2.74, $95 \% \mathrm{Cl} 1.42-5.31$ ), as well as those who were not exclusively breastfed (OR 2.26, 95\% Cl 1.17-4.37).

Conclusions: Orthodontic pacifiers does not favor the development of poor oral habits, even if it has been used for a period of 2 years in children with primary dentition. Children who begin to use orthodontic pacifier between 0 and 3 months, are less likely to acquire fingersucking/thumbsucking habit. The use of an orthodontic pacifier appears not to be correlated with the prevalence of malocclusion in primary dentition, differently from what stated in literature about the conventional type of pacifier.
\end{abstract}

Keywords: Fingersucking, Thumbsucking, Pacifiers, Malocclusions, Tongue habits, Oral habits

\footnotetext{
*Correspondence: simtecc@gmail.com; tecco.simona@hsr.it

Dental School, Vita-Salute San Raffaele University and IRCCS San Raffaele

Hospital, via Olgettina 58, 20132 Milan, Italy

Full list of author information is available at the end of the article
}

(c) The Author(s). 2019 Open Access This article is distributed under the terms of the Creative Commons Attribution 4.0 International License (http://creativecommons.org/licenses/by/4.0/), which permits unrestricted use, distribution, and reproduction in any medium, provided you give appropriate credit to the original author(s) and the source, provide a link to the Creative Commons license, and indicate if changes were made. The Creative Commons Public Domain Dedication waiver (http://creativecommons.org/publicdomain/zero/1.0/) applies to the data made available in this article, unless otherwise stated. 


\section{Background}

The use of pacifiers is accepted during the first year of life, because it decreases the risk of sudden infant death syndrome, due to its influences on autonomic and cardiovascular control; in addition, it could help to calm the children and improve his/her psychological development [1]. Also other non-nutritive habits such as thumbsucking or fingersucking are often implemented by infants/children to pacify and comfort themselves, as sucking is a natural instinct for a baby, and it is the baby's first coordinated muscular activity [1]. However, from the craniofacial development point of view, the use of a conventional pacifier for a long time (over 2 years) [2] and with high frequency (a "daily use", as recently stated by Ling et al. [1]) has been associated with some alterations of the occlusion, such as anterior open bite and posterior crossbite [3-5].

For this reason, the so-called orthodontic pacifiers have been introduced into the market, designed with a flattened nipple to simulate mothers' nipple anatomy, to maintain the necessary pressure of tongue on the palatal vault and to obtain a more acceptable lip seal, allowing its physiological development and reducing the side effects related to utilising conventional pacifiers [6-9]. In fact, the use of such pacifiers would rise to replicate the patterns of muscle contraction, tongue position and nasal breathing similar to the ones occurring during breastfeeding, whereby they would not interfere with the growth and development of the face and occlusion [10].

The first systematic literature review on the differences between conventional and orthodontic pacifiers [11], was not able to draw any conclusion due to the low level of available studies, requesting more data on this field. That systematic review did not include parameters such as frequency and duration of pacifier usage. Another recent systematic review [12] including five trials about the comparison between orthodontic and conventional pacifiers $[6,7,10,13,14]$ concludes that a proper definition for a functional or orthodontic pacifier is missing, and that functional orthodontic pacifiers seem to cause less anterior open bite than conventional ones, while the no statistical difference implies the absence of an association between the prevalence of posterior crossbite and the use of orthodontic pacifiers $[6,10]$. Thus, the main conclusion stated the insufficiency of currently available evidence to support this hypothesis that the usage of orthodontic pacifiers is able to prevent malocclusion traits when compared to conventional ones, and that new data on orthodontic pacifiers effects are necessary in literature to substantiate the argument [8].

Orthodontic pacifiers, while reducing the occurrence of malocclusions, also lessen the risk of gaining those poor oral habits, which are harder to stop in children, for example fingersucking/thumbsucking. In other words, the rationale is that if the child gets the maximum satisfaction from orthodontic pacifier sucking (a non-dangerous sucking), he will not feel the need to acquire other poor habits. In addition, as an orthodontic pacifier can enhance the coordination between breathing and sucking-swallowing by oral stimulation, it could also prevent mouth breathing.

As poor oral habits and mouth breathing may be predisposing factors for formation of malocclusion, $[4,15,16]$ knowledge of orthodontic pacifiers role to contribute or prevents them, could help in determining better options for children's oral health care. But unfortunately, literature still lacks data on the frequency of poor oral habits and breathing pattern among those children using orthodontic pacifiers.

Thus, the aim of this observational study was to investigate the prevalence of poor oral habits and malocclusions, in children using an orthodontic pacifier.

\section{Methods}

In this observational study, conducted at the University of l'Aquila (Central Italy), including a database of customers who gave their consent to Philips S.p.A. (Viale Sarca 235, 20,126 Milano, Italy) to participate in this screening event. The collected data covers purely a group of pre-school children aged 3-5years, who had exclusively used the orthodontic pacifier brand called Philips Avent (Philips S.p.A., Viale Sarca 235, 20,126 Milano, Italy). Then, the parents/legal guardians have been contacted by an Orthodontics residency student from the University of L'Aquila, in order to provide them all the information regarding the research protocol. A free clinical oral examination at the dental clinic of the University was offered to all the contacted parents/legal guardians so as to encourage their participation in the study. The protocol agrees with the declaration of Helsinki and was approved by the ethical committee of the University of L'Aquila and the content validity of the questionnaire has been obtained in a qualitative way. In order to validate the questionnaire, a number of 15 experts in the field of orthodontics have been provided with the question sheet, to evaluate and comment on the grammar, use of proper words, transparency and correct placement of each question and its related answer options. Finally, according to the experts' comments and suggestions, the questions were reconsidered and corrected. Then, the final edited version of the questionnaire was used to proceed with the present study.

The sample size was corresponding to a previously fulfilled cross-sectional study on the same topic, [17] in which the prevalence of malocclusion of $50 \%$, a $95 \%$ confidence interval, and a standard error of $7 \%$ were assumed. The sample size of Lopes Freire et al. included a minimum of 195 children. Thus, during the initial stage a total number of 250 children were contacted. 
About 210 of parents/legal guardians confirmed the participation of their children to the study, and a dental visit appointment has been scheduled for each participant. An informed consent form regarding the study and the dental examination has been handed to the parents at the beginning of the appointment, and it has been signed before clinical examination was carried out. Then, each parents/legal guardian has been provided with a validated questionnaire designed to collect information about the oral habits and general behaviors concerning oral health of their children and they utmost cooperation and honesty were requested while answering the questions. They were also asked not to hesitate to request any clarification in case of unclear questions. Lastly, the children were clinically examined on the dental chair, to determine the presence/absence of malocclusion and crossbite [18].

Tongue thrust swallow, tongue interposition between the dental arches at rest and tongue tie were also evaluated following a clinical protocol [19].

The clinical examination was performed by an experienced specialized orthodontist (S.C.), a principal investigator, with more than 5 years of orthodontic training and blind to the answers given to the questionnaire by the parents/legal guardians. The clinical examination of 15 children was repeated twice after a period of 15-30 days from the first examination, to evaluate the intra-operator method error and to assure that both examinations data agreed for $100 \%$ of the variables for all the children.

After the examination, to maintain the integrity of the study results, data from the assessed participants with severe skeletal discrepancy or craniofacial anomalies as cleft lip or palate, were excluded from the present analyses. In addition, also data from subjects with alterations of number, size and shape of deciduous teeth, or with major tooth destruction/reconstruction, systemic diseases and/or neurological diseases were excluded from analyses.

Therefore, data from a final sample of 198 children aged 3-5 years, with primary dentition were finally included in the present investigation. Ultimately a final data representing a sample of 198 children aged 3-5 years, with primary dentition were included in the present investigation.

\section{Statistical analyses}

The Kolmogorov-Smirnov test was used to realize whether the data is normally distributed. The result of this analysis showed that the data was not normally distributed $(p$-value $=0.00)$. Hosmer \& Lemeshow, VIF (Variance Inflation Factor) and Cook's distance tests were utilized independently to measure the goodness-offit of this logistic model, using R software (3.5.1 version).
A descriptive statistical analysis was conducted to illustrate the characteristics of the sample, the data obtained from the questionnaires, the prevalence of poor oral habits and malocclusions. In order to study the relationship between orthodontic pacifier sucking, poor oral habits and malocclusion, cross-tabulation analysis was performed among variables and the $\chi^{2}$ test was used, providing Odds Ratios (OR) with a 95\% confidence interval (CI) for each significant association.

Then the statistically significant variables were introduced to this logistic regression model, with the presence/absence of malocclusion and poor oral habits, placed as dependent variables.

It has been analyzed to verify whether resulted fitted to the data.

For each analysis, the threshold for statistical significance was set at $p<0.05$.

\section{Results}

Table 1 reports the characteristics and all the results of the present survey. As seen in Table 1, it emerged that most of the children $(79.79 \%, 156$ children out of 198) started using the orthodontic pacifier early, within the first 3 months of life, and often continued using it for a duration over 2 years. Thus, a great part of sample including $43.94 \%$ used the orthodontic pacifier for more than 2 years, while a lower percentage of children $31.82 \%$ used the pacifier for a period up to 2 years. The percentages of children who gladly used their orthodontic pacifier $(78.28 \%, 155$ children out of 198) and those who used it during sleep in the first year of life $(89.39 \%, 177$ children out of 198) were also very high.

When the sample was divided into two groups, based on the presence/absence of a malocclusion, compared to each other, statistically significant differences for gender distribution, with a significantly higher percentage of females with malocclusions compared to the males (63.38\% vs $44.88 \%, p=0.012$ ), and for breastfeeding, which interested a lower proportion of children in the malocclusion group $(71.65 \%$ vs. $57.75 \%, p=0.046)$, were detected. The estimates of the ORs - adjusted for the effects of the other factors - are presented in the model (Table 2), through a logistic regression, that revealed a significant contribution of female gender (OR 2.74, 95\% CI 1.42-5.31), and the not exclusive breastfeeding (OR $2.26,95 \%$ CI $1.17-4.37$ ) in increasing the probability of developing a malocclusion.

The regression revealed a significant contribution of the beginning of orthodontic pacifier sucking on the prevalence of fingersucking/thumbsucking, because children who began to use orthodontic pacifier very early, between 0 and 3 months, were less likely to develop fingersucking/thumbsucking respect to children who begun 
Table 1 Descriptive characteristics of the sample

\begin{tabular}{ll}
\hline Variable & $n(\%)$ \\
\hline Gender & $96(48.48)$ \\
Male & $102(51.52)$ \\
Female & \\
Age & $3-5$ years \\
(in years) &
\end{tabular}

What age did your baby start to use pacifiers at?

$$
\begin{array}{ll}
0-3 \text { months } & 156(78.79) \\
4-6 \text { months } & 26(13.13) \\
7-12 \text { months } & 16(8.08)
\end{array}
$$

How long did your baby use pacifiers?

$$
\begin{array}{ll}
6 \text { months } & 26(13.13) \\
1 \text { years } & 22(11.11) \\
2 \text { years } & 63(31.82) \\
>2 \text { years } & 87(43.94)
\end{array}
$$

Did your baby start to use pacifiers gladly?

$$
\begin{array}{ll}
\text { No } & 43(21.72) \\
\text { Yes } & 155(78.28)
\end{array}
$$

Did your baby use the pacifier during sleep during the first year of life?

$$
\begin{array}{ll}
\text { No } & 21(10.61) \\
\text { Yes } & 177(89.39)
\end{array}
$$

Have you been informed at baby's birth about how to make your baby sleep safely?

$\begin{array}{ll}\text { Yes } & 181(91.41) \\ \text { No } & 17(8.59)\end{array}$

Did your baby suffer recurrent otitis complaints?

$\begin{array}{ll}\text { No } & 178(89.90) \\ \text { Yes } & 20(10.10)\end{array}$

Was your baby exclusively breastfed for the first six months of life?

$$
\begin{array}{ll}
\text { Yes } & 132(66.67) \\
\text { No } & 66(33.33)
\end{array}
$$

Have you been informed at birth about benefits and not using pacifiers?

$$
\begin{array}{ll}
\text { Yes } & 111 \text { (56.06) } \\
\text { No } & 87(43.94)
\end{array}
$$

Did your baby suffer gastro-oesophageal reflux problems (frequent regurgitation, vomiting after meals)?

$$
\begin{array}{ll}
\text { No } & 161(81.31) \\
\text { Yes } & 37(18.69)
\end{array}
$$

Does your child sleep with open mouth?

$$
\begin{array}{ll}
\text { No } & 126(63.96) \\
\text { Yes } & 71(36.04)
\end{array}
$$

Does your child suck his/her finger/thumb?

$$
\begin{array}{ll}
\text { No } & 187(94.44) \\
\text { Yes } & 11(5.56)
\end{array}
$$

Did your baby suffer with weaning?
Table 1 Descriptive characteristics of the sample (Continued)

\begin{tabular}{ll}
\hline Variable & $n(\%)$ \\
\hline Yes & $5(2.54)$ \\
Does the child bite his/her lip? & $187(94.44)$ \\
No & $11(5.56)$ \\
Yes & \\
Does the child bite his/her nails? & $168(84.85)$ \\
No & $30(15.15)$ \\
Yes & $127(64.14)$ \\
Clinical examination: presence of malocclusion \\
No & $71(35.86)$ \\
Yes &
\end{tabular}

Clinical examination: presence of crossbite

$\begin{array}{ll}\text { No } & 162(81.82) \\ \text { Unilateral } & 28(14.14) \\ \text { Bilateral } & 8(4.04)\end{array}$

Clinical examination: presence of tongue thrust swallow

$\begin{array}{ll}\text { No } & 166(83.84) \\ \text { Yes } & 32(16.16)\end{array}$

Clinical examination: tongue interposition between dental arches at rest

$\begin{array}{ll}\text { No } & 173(87.37) \\ \text { Yes } & 25(12.63)\end{array}$

Tongue tie

No 178 (89.89)

Yes $20(10.11)$

after 3 months (OR 0.13, 95\% CI 0.04-0.47, $p=0.0004$ ) (Table 3).

For the model stated in Table 2, the Hosmer and Lemeshow goodness of fit test become non-significant since $P$-value $=1 \quad(\mathrm{X}$-squared $=2.9107 \mathrm{e}-23, \mathrm{df}=2)$. To identify influential outliers, plot of Cook's distance is shown in Fig. 1. There is no influential outliers because of all observation has the Cook's distance less than 1 .

Table 2 Logistic regression analysis for the development of malocclusion and the explanatory variables (gender, breastfeeding)

\begin{tabular}{lll}
\hline Risk factor & $\mathrm{OR}^{\circ}$ & $95 \% \mathrm{Cl}$ \\
\hline $\begin{array}{l}\text { Gender } \\
\text { Males }\end{array}$ & & \\
Females & 1 & $(1.42-5.31) *$
\end{tabular}

Was your baby exclusively breastfed for the first six months of life?

$$
\text { Yes }^{\#} \quad 1 \quad(1.17-4.37) *
$$$$
\text { No } 2.26
$$

$95 \%$ Cl 95\% confidence interval

\#Reference category

* Statistically significant association

${ }^{\circ}$ adjusted ORs for the other factors in the model 
Table 3 Logistic regression analysis for the association between development of fingersucking/thumbsucking and the age of beginning of orthodontic pacifier sucking)

\begin{tabular}{lcc}
\hline Risk factor & $\mathrm{OR}^{\circ}$ & $95 \% \mathrm{Cl}$ \\
\hline Age of beginning of orthodontic pacifier use: & \\
$>3$ months $^{\#}$ & 1 & \\
$0-3$ months & 0.13 & $(0.04-0.47) *$ \\
\hline
\end{tabular}

95\% Cl 95\% confidence interval

"Reference category

* Statistically significant association

${ }^{\circ}$ adjusted ORs for the other factors in the model

VIF for two predictors Gender, and Breastfeeding is 1.033. So we see from the output of the VIF function, that the variables Gender and Breastfeeding are not collinear.

For the model stated in Table 3, Hosmer and Lemeshow test with $p$-value $=1$ (X-squared $=3.045 \mathrm{e}$ $27, \mathrm{df}=2$ ) suggests a good fit for the data. Further, since all points for Cook's distance is less than 1, we can conclude that there is no influential outliers (see Fig. 2). Hence two models adequately describe the data.

No other associations were detected among the poor habits and the orthodontic pacifier sucking.

\section{Discussion}

This observational study aimed to evaluate the prevalence of poor oral habits and malocclusions among children after using an orthodontic type of pacifier. The sample (198 children, ranging between 3 and 5 years of age) is undoubtedly the most extensive report among

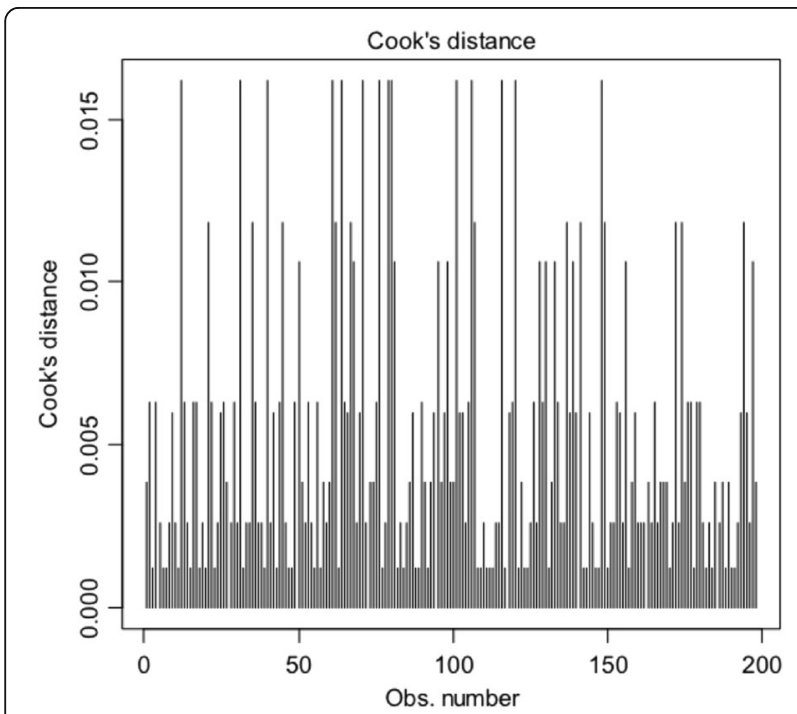

Fig. 1 Cook's distance plot to find influential outliers for model 1 , the development of malocclusion and the explanatory variables (gender, breastfeeding)

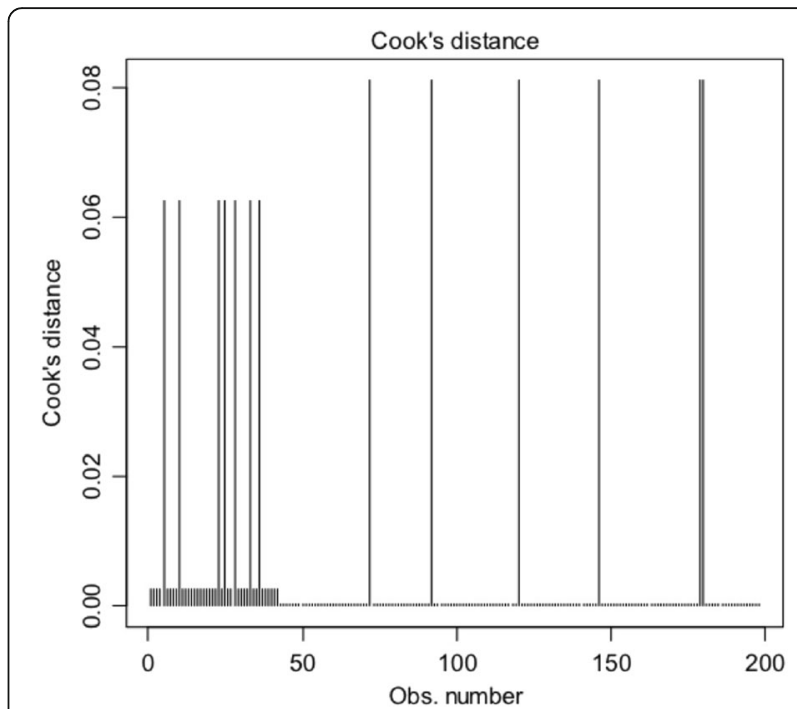

Fig. 2 Cook's distance plot to find influential outliers for model 2 (development of fingersucking/thumbsucking and the variable age of beginning of orthodontic pacifier sucking)

the published literature, recording the data of children who have exclusively used an orthodontic pacifier. Thus, the collected data can be generalized for the population of children who use orthodontic pacifiers. In addition, previously, no study has looked into whether or how orthodontic pacifier sucking is interrelated with poor oral habits, mouth breathing and tongue thrust swallow.

In the present sample, the great part of children (78.28\% of the whole sample) gladly started utilizing orthodontic pacifier during their first 3 months of life (78.79\% of the whole sample), adopting it regularly throughout the night, in their first year of age $(89.39 \%$ of the whole sample). Thus, the present data can confirm that orthodontic pacifier was generally well accepted by children, as this fact has already been reported in various literatures $[6,10,20]$. In addition, the collected data of the present study revealed that the $91.41 \%$ of the parent/ guardians had been properly informed right from the beginning about the advantages of orthodontic pacifiers over the conventional types and also the risks related to its prolonged usage. This also has been outlined that a great number of children were given their pacifiers during the night (89.39\% of the whole sample), following the recommendations of pacifier usage, i.e. that it should be used while the infant is sleeping and not reinserted if the child drops it during sleep [21] (today, the recommended usage would be for sleeping and for less than 4-6h per day) [22]. These data are in close agreement with the fact that an orthodontic pacifier is adopted by those mothers who are adequately informed concerning the risks of using conventional pacifiers. The present data also indicate that no significant correlation was detected between the duration of the pacifier sucking and 
the prevalence of recurrent otitis, as recurrent otitis was recorded only for 20 children out of 198 (10.10\%). Differently from another previous report, which observed that pacifier sucking for a period exceeding 10 months, increases the risk of recurrent otitis [23].

Mouth breathing during the night was present in 71 children out of 198 (36.04\% of the sample). The result of present study suggests that there exists a predominant pattern of nasal breathing among participated children. While, no relationship can be deduced between the breathing pattern and orthodontic pacifier sucking.

This result agrees with a recent survey from a sample of 1405 children between the ages of 2 and 7 , (699 females and 706 males), in which oral breathing was present in $26.3 \%$ of the total children, concluding for the great benefits of an early interceptive treatment, as it is categorized as grade 2 of risk, requesting a periodical surveillance, and ear, nose, and throat evaluation for breathing problems. [24]

In a previous sample of 36 pre-school children with primary dentition using conventional pacifier, Nihi et al. found that $22.2 \%$ of them (8 subjects out of 36 ) had mouth breathing at rest, while only $8.3 \%$ ( 4 children out of 48) of pacifier non-users showed mouth breathing [2]. According to Nihi et al. a higher prevalence of mouth breathing among pacifier users with respect to controls, may be associated to the altered position of the tongue in the mouth, which causes these subjects to keep their mouths open and consequently develop a mouth-breathing pattern. This explanation may be justifiable both for children using conventional as well as orthodontic pacifiers, although the present data seem to be insufficient to validate any correlation between pacifier sucking and mouth breathing. Therefore, it may be concluded that the pacifier sucking is not strongly related to breathing pattern during the night.

The result of present observational study, reveals that the tongue thrust swallow affected $16.16 \%$ of the sample (32 children out of 198), and no significant dependency could be established with pacifier sucking beginning or its duration. In the sample analyzed by Nihi et al., tongue thrust swallow was detected in $27.8 \%$ (10 out of 36 subjects), a percentage higher than that of the present study (16.16\%; 32 children out of 198) [2]. Nihi et al. associate the tongue thrust swallow with a prolonged pacifier-sucking habit, which delays maturation of the swallowing reflex. The present data suggest that an orthodontic pacifier thin neck nipple structure could be helpful to reduce the occurrence of tongue thrust swallow, as also hypothesized previously [13]. With regard to the poor oral habits, $5.56 \%$ of the present sample (11 children out of 198) reported fingersucking/thumbsucking, but no relationship was detected between breastfeeding and fingersucking/ thumbsucking. In addition, those children who began to use orthodontic pacifier very early - between 0 and 3 months of life - showed a lower risk to develop fingersucking/thumbsucking habit in respect to children who begin after 4 months (OR 0.13, 95\% CI 0.04-0.47, $p=0.0004$ ) (Table 3). This result is in an acceptable agreement with the recommendation of both Canadian and American Dental Associations, which suggest pacifiers out of finger/ thumb sucking, as it would be more convenient for parents to control the sucking habit, as it is easier to wean a child's habit from a pacifier, than from a thumb $[25,26]$.

This finding appears to disagree with what is generally believed for conventional pacifiers, i.e. that if conventional pacifiers are given to infants in the early postpartum period, when they are learning to suck from their mothers' breasts, its use may act as a favour for a later fingersucking/thumbsucking habit development [27]. In agreement with this statement, Ling et al. reported, from a sample of 1034 Asian children aged 2 to 5 years old, that children who use conventional pacifiers "daily" have significantly higher chances of developing fingersucking/ thumbsucking habits [1], while the present study does not confirm this association in the case of orthodontic pacifiers. The present data states the opposite concept, i.e. children who began to use orthodontic pacifier during the first 3 months of life are less likely to develop fingersucking/thumbsucking with respect to children who had begun after 4 months (OR 0.13, 95\% CI 0.040.47, $p=0.0004$ ). It must be noted that Ling et al. report data on conventional pacifiers, and did not analyze the beginning of the pacifier sucking, but only its frequency (a "daily" use or "not daily" use) (OR 2.136; 95\% CI 1.11-4.10) [1]. These factors provide satisfactory explanation concerning the different conclusions between the two studies. To the authors best knowledge there is no published work on the relationship between pacifier sucking and fingersucking. The only study performed is the one reported in 1977, the author came to the conclusion that there exists an inverse relation between two habits [28] this is quite compatible with the results obtained in the present study.

Thus, it is not difficult to draw a conclusion that the infants who begin early to use orthodontic pacifiers may experience a kind of satisfaction and this can reduce the urge for further addiction, preventing the development of other poor oral habits.

About the other poor oral habits, the proportions of children having the habits of lip biting, tongue interposition between dental arches, or nail biting were $5.56 \%$ (11 children out of 198), 12.63\% (25 children out of 198) and $15.15 \%$ (30 children out of 198), respectively. In addition, the use of an orthodontic pacifier for more than 2 years seems not to favor the acquisition of additional poor oral habits, even when used for more than 
2 years. These percentages appear low and acceptable, if compared with a general population of 1405 preschool children between the ages of 2 and 7 (699 females and 706 males), similar to recently analyzed study in which a percentage of $27.5 \%$ of children having bad oral habits was observed. [24]

In addition, no association was detected between the duration or the beginning of orthodontic pacifiers sucking, and the frequencies of these poor oral habits. These data suggest that orthodontic pacifier sucking doesn't cause the dependency to other poor oral habits. Only a few studies in literature had analyzed the relationship between pacifier sucking and other poor oral habits. About the tongue interposition between dental arches at rest, it was previously investigated in a sample of 36 preschool children with primary dentition using conventional pacifiers, and it was observed in $38.9 \%$ of children (14 subjects out of 36) [2], a percentage higher respect to the present study of $12.63 \%$ ( 25 children out of 198).

In general, the low frequencies of poor oral habits in the present sample could indicate that the use of orthodontic pacifiers do not represent a promoting factor. Despite what reported about conventional pacifiers, it could be hypothesized that infants could experience improved safety and satisfaction due to the unrestricted sucking, as previously reported for breastfeeding [1] and thus no other sucking actions are needed, leading to a low frequency of fingersucking/thumbsucking and other poor oral habits in children using orthodontic pacifiers.

With regard to the prevalence of malocclusions, in the present study, all the various types of malocclusions hypothetically correlated to poor oral habits were summarized together in a unique variable (i.e. "malocclusions"). The logistic regression failed to evidence any correlation between orthodontic pacifier sucking and the presence of malocclusions in the present sample, as only the gender and the breastfeeding variables were significantly related to the prevalence of malocclusion (Table 2). Also, the duration of using orthodontic pacifier was not associated to the prevalence of malocclusions. This could be considered an interesting finding, as malocclusion in the deciduous dentition represents a risk factor for the necessary orthodontic treatment of permanent dentition [29].

In the present sample, 36 children out of 198 (18.18\% of the sample) showed a posterior crossbite ( 28 children showed unilateral crossbite, and 6 children showed bilateral crossbite). The prevalence of posterior crossbite in children using conventional pacifiers varies from 12.8 to $88.9 \%$, as evaluated in a recent systematic review [12]. But in a sample of 55 children using orthodontic pacifiers, Lima et al. [10] reported only 4 cases out of 55 having posterior crossbite (7.27\%). To explain the difference with the present sample, we should consider that
Lima et al. recorded a very low prevalence of crossbite ( 6 children out of 55 , i.e. less than $10 \%$ of the sample) even among children using conventional pacifiers. Thus, the results observed from Lima et al. [10] could be associated not only to the type of pacifier, but probably to the lower mean age of children, that was $28.2 \pm 1.9$ months (with an initial age range for selection of subjects indicated as 12-24 months) in their sample, while in the present study the age of the children ranged between 3 and 5 years. Furthermore, Lima et al. excluded subjects with enlarged adenoids or respiratory problems, with history of finger sucking, lip sucking, lip biting and lingual interposition, while in the present sample these exclusion criteria were not adopted. Thus, the percentage observed in the present sample appear more generalizable to the population of children adopting orthodontic pacifiers.

From the present data, no significant correlation was found out between the beginning of using orthodontic pacifier, its duration, and the frequency of crossbite. Previous literature based on conventional pacifiers, strongly correlates the posterior crossbite with the duration of the habit, until 4-6 years of age [30], and with the use of a pacifier for more than 36 months [31], more than 2 years [2], more than 15.5 months [6], or more than 1 year [1]. The present observation suggests that the design of the orthodontic pacifier doesn't promote the occurrence of posterior crossbite, even when used for more than 2 years.

Most of the previous literature state that with a long duration and high frequency of conventional pacifier usage, there is a tendency to hyperfunction of the buccinator muscle, which causes a deficiency in transverse growth of the maxilla and increased frequency of crossbites. Differently, orthodontic pacifiers are designed to avoid hyperfunction of the buccinator muscle. However, some previous studies on conventional pacifiers failed to evidence for an association between posterior crossbite and pacifier sucking. For example, Moimaz et al. could not find any statistically significant difference concerning posterior crossbite between the patients with or without previous usage of a pacifier at 12,18 , and 30 months, except when the posterior crossbite was associated with fingersucking [32-34]. The present data did not reveal any relationship between the orthodontic pacifier sucking and the posterior crossbite, even when associated with fingersucking/thumbsucking. The present findings suggest that the use of an orthodontic pacifier should be not correlated to the prevalence of malocclusions in primary dentition, differently from what reported in literatures concerning the usage of conventional pacifiers.

At the end, this fact could be substantiated that contrary to popular belief regarding pacifier usage, an orthodontic type of pacifier has no effect on neither 
development of malocclusion, nor poor oral habits, this can be one of the considerable points to make orthodontic pacifier more preferable to the conventional ones.

\section{Limitations of the study}

This observational study was subjected to some limitations. A longitudinal design with an additional follow-up would be useful, especially for monitoring those children that used the pacifier for more than 2 years. Anyway, it should be noted that the present report did not indicate any higher risk of malocclusion for children with more than 2 years of pacifier usage with respect to those children with less prolonged usage, that confounders were reported, and adjustments for non-nutritive sucking habits were performed, trying to avoid biased results. It should also be considered that owing to its design, this study could be susceptible to recall bias. Finally, as parents are unable to monitor their children for $24 \mathrm{~h}$ per day, there may be an underestimation of the true level of poor oral habits.

\section{Conclusions}

The use of orthodontic pacifiers does not promote the occurrence of poor oral habits in children with primary dentition, despite its prolonged usage. An early orthodontic pacifier's usage beginning ( $0-3$ months) seems to be associated with a reduced risk of developing fingersucking/thumbsucking habit. The use of an orthodontic pacifier seems not to be related to the development of malocclusions in primary dentition differently from what previously reported in literature for conventional pacifiers. Further prospective controlled studies are encouraged to confirm what reported in the present study about the relationship between the use of orthodontic pacifiers and the incident of malocclusions and poor oral habits.

\section{Abbreviations}

95\% Cl: 95\% Confidence interval; Cl: Confidence interval; OR: Odds ratio; SPSS: Statistical Package for Social Science

\section{Acknowledgements}

The authors would like to thank the Philips S.p.A. for the value database and all the university staff for their support and advice throughout the study course. We thank the families who participated in the study.

\section{Author's contributions}

SC: concept, design, clinical procedures, data collection, methodology, approval of the article.AN: concept, design, writing of the article, methodology, critical revisions, approval of the article.AD: design, writing of the article, methodology, critical revisions, approval of the article.MS: data collection, article revision, approval of the article.RG: concept and direction of clinical procedures, critical revision of the manuscript, accountability for research integrity and accuracy, final approval of the article.ST: concept, design, writing of the article, methodology, critical revisions, approval of the article. All authors have read and approved the manuscript.

\section{Funding}

No funding was received for this study. The study was spontaneous.

\section{Availability of data and materials}

The data that support the findings of this study are available from the University of L'Aquila, but restrictions are applied to the availability of these data, which were used under license for the current study, and so are not publicly available. Data are however available from the authors upon reasonable request and with permission of the University of L'Aquila.

Ethics approval and consent to participate

Informed consent was obtained for participants from their legal representatives, as appropriate, in written form. This study was approved by the ethical committee of the University of L'Aquila.

\section{Consent for publication}

Not applicable.

\section{Competing interests}

The authors declare that they have no competing interests.

\section{Author details}

'Department of Life, Health and Environmental Science (MeSVA), University of L'Aquila, Piazzale Salvatore Tommasi 1, Blocco 11, 67100 L'Aquila, Coppito, Italy. ${ }^{2}$ Dental School, Vita-Salute San Raffaele University and IRCCS San

Raffaele Hospital, via Olgettina 58, 20132 Milan, Italy.

Received: 21 February 2019 Accepted: 14 August 2019

Published online: 22 August 2019

\section{References}

1. Ling HTB, Sum FHKMH, Zhang L, Yeung CPW, Li KY, Wong HM, et al. The association between nutritive, non-nutritive sucking habits and primary dental occlusion. BMC Oral Health. 2018;18:145. https://doi.org/1 0.1186/s12903-018-0610-7.

2. Nihi VSC, Maciel SM, Jarrus ME, Nihi FM, de SCLF, Pascotto RC, et al. Pacifiersucking habit duration and frequency on occlusal and myofunctional alterations in preschool children. Braz Oral Res. 2015;29:1-7.

3. Tecco S, Caputi S, Festa F. Evaluation of cervical posture following palatal expansion: a 12-month follow-up controlled study. Eur J Orthod. 2007:29: 45-51. https://doi.org/10.1093/ejo/cjl021.

4. Majorana A, Bardellini E, Amadori F, Conti G, Polimeni A. Timetable for oral prevention in childhood--developing dentition and oral habits: a current opinion. Prog Orthod. 2015;16:39.

5. Doğramacı EJ, Rossi-Fedele G. Establishing the association between nonnutritive sucking behavior and malocclusions. J Am Dent Assoc. 2016;147:926-934.e6

6. Adair SM, Milano M, Lorenzo I, Russell C. Effects of current and former pacifier use on the dentition of 24- to 59-month-old children. Pediatr Dent. 1995;17:437-44

7. Zimmer S, Barthel CR, Ljubicic R, Bizhang M, Raab WHM. Efficacy of a novel pacifier in the prevention of anterior open bite. Pediatr Dent. 2011;33:52-5.

8. Medeiros R, Ximenes M, Massignan C, Flores-Mir C, Vieira R, Porporatti AL, et al. Malocclusion prevention through the usage of an orthodontic pacifier compared to a conventional pacifier: a systematic review. Eur Arch Paediatr Dent. 2018:19:287-95.

9. Ballanti F, Baldini A, Ranieri S, Nota A, Cozza P. Is there a correlation between nasal septum deviation and maxillary transversal deficiency? A retrospective study on prepubertal subjects. Int J Pediatr Otorhinolaryngol. 2016;83:109-12. https://doi.org/10.1016/i.jporl.2016.01.036.

10. Lima AADSJ, Alves CMC, Ribeiro CCC, Pereira ALP, da Silva AAM, Silva LFGE, et al. Effects of conventional and orthodontic pacifiers on the dental occlusion of children aged 24-36 months old. Int J Paediatr Dent. 2017;27:108-19.

11. Corrêa C de C, Bueno M da RS, Lauris JRP, Berretin-Felix G. Interference of conventional and orthodontic nipples in system stomatognatic: systematic review. CoDAS. 2016;28:182-9.

12. Schmid KM, Kugler R, Nalabothu P, Bosch C, Verna C. The effect of pacifier sucking on orofacial structures: a systematic literature review. Prog Orthod. 2018;19:8

13. Wagner $Y$, Heinrich-Weltzien R. Effect of a thin-neck pacifier on primary dentition: a randomized controlled trial. Orthod Craniofac Res. 2016;19:127-36.

14. Zimmer S, Zuralski H, Bizhang M, Ostermann T, Barthel CR. Anterior open bite in 27 months old children after use of a novel pacifier - a cohort study. J Clin Pediatr Dent. 2016;40:328-33. 
15. Saccucci M, Tettamanti L, Mummolo S, Polimeni A, Festa F, Tecco S. Scoliosis and dental occlusion: a review of the literature. Scoliosis. 2011;6:15.

16. Mummolo S, Nota A, Caruso S, Quinzi V, Marchetti E, Marzo G. Salivary markers and microbial Flora in mouth breathing late adolescents. Biomed Res Int 2018. 2018:8687608. https://doi.org/10.1155/2018/8687608.

17. Lopes Freire GM, Espasa Suarez de Deza JE, Rodrigues da Silva IC, Butini Oliveira L, Ustrell Torrent JM, Boj Quesada JR. Non-nutritive sucking habits and their effects on the occlusion in the deciduous dentition in children. Eur J Paediatr Dent. 2016;17:301-6.

18. Grippaudo C, Paolantonio EG, Pantanali F, Antonini G, Deli R. Early orthodontic treatment: a new index to assess the risk of malocclusion in primary dentition. Eur J Ped Dent. 2014;15:401-6.

19. Maspero C, Prevedello C, Giannini L, Galbiati G, Farronato G. Atypical swallowing: a review. Minerva Stomatol. 2014;63:217-27.

20. Zardetto CG del C, Rodrigues CRMD, Stefani FM. Effects of different pacifiers on the primary dentition and oral myofunctional strutures of preschool children. Pediatr Dent. 2002;24:552-60.

21. American Academy of Pediatrics Task Force on Sudden Infant Death Syndrome. The changing concept of sudden infant death syndrome: diagnostic coding shifts, controversies regarding the sleeping environment, and new variables to consider in reducing risk. Pediatrics. 2005;116:1245-55.

22. Warren JJ, Levy SM, Nowak AJ, Tang S. Non-nutritive sucking behaviors in preschool children: a longitudinal study. Pediatr Dent. 2000;22:187-91.

23. Niemelä $M$, Uhari $M$, Möttönen $M$. A pacifier increases the risk of recurrent acute otitis media in children in day care centers. Pediatrics. 1995:96(5 Pt 1):884-8.

24. Grippaudo C, Paolantonio EG, Luzzi V, Manai A, La Torre G, Polimeni A. Orthodontic screening and treatment timing in preschoolers. Clin Exp Dent Res. 2019;5(1):59-66.

25. Canadian Paediatric Society. Reccomendation for the use of pacifiers. Paediatr Child Health. 2003;8:515-9.

26. American Dental Association. Your child's teeth. Chicago: American Dental Association; 2002.

27. Aarts C, Hörnell A, Kylberg E, Hofvander Y, Gebre-Medhin M. Breastfeeding patterns in relation to thumb sucking and pacifier use. Pediatrics. 1999;104:e50

28. Zadik D, Stern N, Litner M. Thumb- and pacifier-sucking habits. Am J Orthod. 1977:71:197-201.

29. Peres KG, Peres MA, Thomson WM, Broadbent J, Hallal PC, Menezes AB. Deciduous-dentition malocclusion predicts orthodontic treatment needs later: findings from a population-based birth cohort study. Am J Orthod Dentofac Orthop. 2015;147:492-8. https://doi.org/10.1016/j.ajodo.2014.12.019.

30. Scavone H, Ferreira Rl, Mendes TE, Ferreira FV. Prevalence of posterior crossbite among pacifier users: a study in the deciduous dentition. Braz Oral Res. 2007;21:153-8 http://www.ncbi.nlm.nih.gov/pubmed/17589651.

31. de Sousa RV, Ribeiro GLA, Firmino RT, Martins CC, Granville-Garcia AF, Paiva SM. Prevalence and associated factors for the development of anterior open bite and posterior crossbite in the primary dentition. Braz Dent J 2014;25: 336-342. http://www.ncbi.nlm.nih.gov/pubmed/25250499.

32. Moimaz SAS, Garbin AJÍ, Lima AMC, Lolli LF, Saliba O, Garbin CAS. Longitudinal study of habits leading to malocclusion development in childhood. BMC Oral Health. 2014;14:96. https://doi.org/10.1186/1472-6831-14-96.

33. Marino A, Nota A, Caruso S, Gatto R, Malagola C, Tecco S. Obstructive sleep apnea severity and dental arches dimensions in children with late primary dentition: An observational study. CRANIO ${ }^{\oplus}$. 2019. p. 1-6.

34. Tecco S, Baldini A, Mummolo S, Marchetti E, Giuca MR, Marzo G, Gherlone EF. Frenulectomy of the tongue and the influence of rehabilitation exercises on the sEMG activity of masticatory muscles. J Electromyogr Kinesiol. 2015; 25(4):619-28

\section{Publisher's Note}

Springer Nature remains neutral with regard to jurisdictional claims in published maps and institutional affiliations.

Ready to submit your research? Choose BMC and benefit from:

- fast, convenient online submission

- thorough peer review by experienced researchers in your field

- rapid publication on acceptance

- support for research data, including large and complex data types

- gold Open Access which fosters wider collaboration and increased citations

- maximum visibility for your research: over $100 \mathrm{M}$ website views per year

At $\mathrm{BMC}$, research is always in progress.

Learn more biomedcentral.com/submissions 